\title{
Teacher collaboration in CLIL contexts: challenges and good practices
}

\author{
Irina Ivanova*
}

\begin{abstract}
Teaching a subject in a foreign language requires a specialist pedagogical expertise from both subject and language teachers whose collaboration is vital for achieving success in CLIL classrooms. Different models of collaboration between teachers in class might be used and experimented with in different lessons, so that the most suitable models be found for each specific teaching and learning context. The article discusses some issues and good practices in teacher collaboration, lesson planning and team teaching in different CLIL contexts. The discussion is based on lesson plan analysis and lesson observations conducted in four European countries under an Erasmus + project.
\end{abstract}

Key words: CLIL, teacher collaboration, lesson planning, team teaching

\section{Introduction}

Content and Language Integrated Learning (CLIL), which is probably the fastest growing teaching paradigm in Europe in recent years, has become a much sought-after epitome of innovation, progressive thinking and development in education, to the extent that "teaching through one single language is seen as second rate education" (Lorenzo 2007: 35). Although as a form of bilingual education CLIL is descendant of North American teaching models, such as the French immersion programmes and Content-based instruction (CBI), it is a distinctly European phenomenon as it is deeply rooted in the European Union policies and needs for plurilingualism and intercomprehension (Munoz 2007; Wolff 2005). Stemming from the ideas of integration, globalisation and modernisation of education, CLIL is defined as "a generic term to describe all types of provision in which a second language (a foreign, regional or minority language and/or another official state language) is used to teach certain subjects in the curriculum other than the language lessons themselves" (Euridice 2006: $8)$.

Unlike immersion programmes and $\mathrm{CBI}$, however, which give priority to language education, CLIL sees language as a vehicle through which content is learnt. As Coyle points out, its distinctiveness lies in that it integrates language and content along a continuum, in a flexible and dynamic way, without an implied preference for either (Coyle 2006, 2007). Perez-Canado, summarising recent recearch on CLIL in Europe, points out that the main differences between

* University of Shumen, Department of English Studies, Shumen, Bulgaria 


\section{CLIL and bilingual education can be found}

in the lesser command of the language of instruction which CLIL teachers evince in general, in the later starting age and lower amount of exposure to the target language in this type of program, in its use of abridged rather than authentic materials, in the fact that the content taught is taken from academic subjects or disciplines rather than from everyday life or the target language culture, in the greater absence of immigrant students within them, and in the comparatively meager amount of research into its effects, as opposed to those of immersion (Perez-Canado 2012: 318).

Research shows that different forms and models of CLIL are being widely implemented in Europe and adapted to a variety of educational and linguistic contexts, so that it is difficult to present a general model of CLIL common to all educational contexts (Euridice network 2012). Back in 2007 Coyle, for example, listed 216 different CLIL programmes, which varied in terms of their compulsory status, intensity, age of onset, starting linguistic level, or duration. The most common type of CLIL programme seems to be based on the combination of a foreign language (English being the most widely taught language across Europe) and a subject, such as History, Geography, Science (depending on teachers' qualifications), particularly in secondary education (see Perez-Canado 2012). The conceptualisation behind the variety of different CLIL programmes is based on the integration of the $4 \mathrm{Cs}-$ content, communication, cognition, and culture (Coyle 2007; Coyle, Hood, Marsh 2010) which define both teaching aims and learning outcomes, and the interrelation of BICS (Basic Interpersonal Communicative Skills) for less cognitively demanding tasks, and CALP (Cognitive Academic Language Proficiency) - for the more demanding language required for academic school study (see Cummins 2001).

Irrespective of the particular language or subject, however, the success of CLIL implementation depends on the collaboration of the language and the subject teacher, who work together towards creating a form of instruction which is most conducive to students' learning.

Teacher collaboration is seen as a necessary prerequisite for teachers' personal professional development. What is more, collaboration in instructional teams within a school or across several schools is considered important for improving students' achievement levels (see Ronfeldt, Farmer, McQueen, Grissom 2015).

Collaboration is a broader term which involves different forms of teacher interaction, one form of which, particularly relevant to our discussion, is team teaching. By definition, team teaching involves "a group of instructors working purposefully, regularly, and cooperatively to help a group of students learn" (Buckley 2000: 4). CLIL as an interdisciplinary approach naturally entails teacher collaboration in preparation and teaching of the lesson, although only some of CLIL contexts are characterised by consistent team teaching practices. There are different models of team collaboration. According to Sandholtz 
(2000), there are three main configurations: 1) two or more teachers loosely sharing responsibilities; 2) team planning, but individual instruction; and 3) joint planning, instruction, and evaluation of learning experiences. Maroney (1995) identified 5 team teaching styles (TT styles) depending on teachers' strengths and competences and students' needs. These involve:

- standard TT: both teachers actively share in instruction;

- collaborative TT: similar to standard TT, yet students learn solely in group formats, sometimes referred to as Total Collaborative Learning;

- complimentary/ supportive TT: one teacher is in charge of content teaching, the other focuses on reinforcement activities or skill building;

- parallel TT: students are divided at random and each teacher is responsible for the learning of their group;

- differentiated TT: similar to parallel TT, yet students are grouped according to learning needs/ levels.

These models refer to team teaching in general and are not directly applicable to CLIL contexts in which the language and content teachers should additionally negotiate their roles and plan their participation in the lesson. In doing so they should rely mainly on their experience and intuition as there are no clear guidelines or models to follow. Teacher training is offered by some pre- and inservice institutions around Europe but since educational policies and stakeholder expectation differ in different countries, there is no unified training provided. Currently almost all EU states implement some form of CLIL with varying degrees of success in compulsory education (Eurydice Network 2012) and there are also a lot of extra-curricular activities and a variety of educational projects aimed at CLIL development and implementation.

\section{Background}

The discussion of good practices and problematic aspects in team collaboration and team planning and teaching is based on lesson plan analysis and lesson observations made under the Erasmus plus project Schools: Future labs, which took place in 2015-2016 in both state and private secondary schools in four European countries: Bulgaria, Greece, Poland, and Romania. The project, which is still in progress, involves representatives of policy makers (Ministries of Education), higher teacher training institutions (Universities), teachers of languages and subjects from the state and the private sector and the students in the respective secondary schools. What makes the project stand out among other CLIL-related projects, is first of all, its STEM (Science, Technology, 
Engineering, and Mathematics) orientation, second - the choice of language German and Spanish, studied as first foreign language in the selected schools, and third - the use of Mobile labs, providing students with hands-on experience in learning-by-doing.

The schools participating in the project provide different contexts for CLIL implementation. In Bulgaria there is one smaller private school with German as a first foreign language and a big comprehensive school with Spanish as a first language. Both schools are in Sofia. From Romania there are two state schools - one in the capital and one in a smaller town with students whose first foreign language is Spanish in the first school, and German - in the second. The only participating school in Greece is a big private school in Athens, where German is taught in small classes as a first foreign language. The school in Poland is a community school with small classes studying Spanish as a first language.

The lesson observations were carried out with the aim of monitoring the process of implementing the project programme. By the time of the obserbations all students had already had a series of lessons in the respective subject (Physics, Chemistry, or Biology) and had had some experience working with the mobile labs purchased for the purposes of the project. The observed lessons were planned in advance, following the CLIL observation checklist produced under the project. The checklist is organized into 4 groups of indicators related to: 1 . Lesson structure, design, and outcomes; 2 . Teaching and learning strategies; 3. Content, language, and communication; and 4. Classroom and Learning process management/ Mobile Labs.

\section{Analysis and discussion}

As an educational approach CLIL is concerned mainly with the classroom and the teaching and learning processes taking place in its immediate context. However, the process of planning which remains hidden for the observer is equally important for achieving success in class. Therefore, bottom-up research - from planning to its realization, is the best approach in the situation.

\section{Planning the lessons - good practices, challenges, and recommendations}

The lesson plans for the observed lessons and those preceding (and following) them were uploaded on the Moodle platform of the project. All plans followed the same mutually agreed template which reflected the main stages of a CLIL inquiry based on doing experiments and working with the mobile labs, starting with a trigger stage, forming and stating a hypothesis, experimentation (processes/results) for verification of the hypothesis, followed by a conclusion and transfer, generalisation and application of the results. Before planning for the stages, the teachers had to think about the prerequisites or requirements for 
the present lesson, and briefly outline its content in terms of the studied subject matter. This was important in order to ensure continuity and make the effect of learning more lasting.

The first challenge for the subject and language teachers was to plan a lesson together - something they have never done before. Agreeing and negotiating the content of the lesson in terms of the subject matter, the nature and the amount of language work, the time students need for conducting the experiments, and the time they need to describe and analyse the results, made the planning process extremely demanding. The template itself was also new to teachers - it follows the stages of an experimental enquiry, and so should have been more familiar to subject teachers, which was not necessarily the case, since traditional subject teaching in participating countries is done primarily in a lecture mode with little involvement or active participation of the students. Reviewing the plans one has the impression that they were not used as an active tool for channeling and facilitating teachers' thinking about the lesson, but were written later when the decisions about the lesson content and structure were already made.

The subject teachers had the leading role in choosing or deciding on the lesson content. Their decisions were usually motivated in the first place by their knowledge of what subject matter is taught in the respective subject (Physics, Chemistry, or Biology) to students of that age, and second, by the options presented by the mobile lab. Once the topic was chosen, the subject teacher decided on the experiments and activities to be done with the mobile lab. Then the experiment(s) were planned by both teachers who had to choose appropriate tasks and target language (key terms and communication patterns) for each stage of the lesson.

Some teachers found the trigger stage (the first stage in the plan template) challenging, as they were not sure about its purpose and meaning. Its aim in general is to trigger students' interest by providing a context through revision of studied material, previous or background knowledge, or providing input related to the topic in the form of reading/listening/visual material. The trigger should then lead to forming a hypothesis which in turn has to be tested through experiments with the mini laboratory equipment. Experiments take the central part of the lesson. They are time-consuming and require careful, clear and staged instructions, and close monitoring and assistance (when needed) by the teachers. Once the experiments are finished, the students have to summarise the results and formulate conclusions which confirm or repudiate the hypothesis. The final stage of the lesson should be dedicated to transferring the obtained knowledge to real-life contexts, making generalisations and finding examples of application of the findings to local or wider contexts.

The second challenge to the teachers was to formulate the aims of the lesson, which were to be planned with respect to the 4 Cs (Content, Communication, 
Cognition, and Culture), so that they reflect students' benefits in terms of the 4 Cs. The aims were not always phrased as aims, and were not differentiated for each phase of the lesson.

Other sections of the plan which posed difficulties for the teachers were those specifying student and teacher activity, which were presented as separate columns in the plan template. The review of the plans leaves one with the impression that teachers should plan for a greater student involvement, a finding in line with research finding that student participation decreases in the CLIL classroom (see Dalton-Puffer et al. 2008).

Whereas student activity section is more descriptive - describes what students do at each stage of the lesson (which should correspond to the tasks in the worksheets), teacher activity section should reflect the variety of teacher roles (e.g. facilitator, manager, monitor, assessor, etc.) during the lesson with a clear focus on students autonomy and the ways the teacher/teachers scaffold students' cognitive development and language acquisition. In some plans there was very little or no variety in the description of teacher activities. What is more, in the cases when the lesson is to be co-taught by both teachers, their participation and the exact role they have in each activity should be clearly specified. This is particularly important if teachers do not have any experience in team teaching, which was the case in all schools involved in the project.

Another problem, identified in the review of the lesson plans, was that planning interaction patterns (social forms of work) did not always reflect the nature of the tasks. Getting students to discuss something in pairs or to brainstorm ideas in a whole-class format depends on the respective task objectives. However, in some plans the variety of patterns was not justified by the nature of the activity. As a rule, language teachers are more used to having a variety of interaction patterns in a lesson, and they should be able to suggest the appropriate ones and negotiate their use with the subject teachers. The chosen formats should create the most favourable conditions for achieving task results, should be specified for each stage and justified in the objectives section. This is in line with the requirement to plan for a balance between teacher-led and student-initiated and controlled activities.

The section which specifies the use of materials and mobile labs should contain a clear indication of reference to these materials - all handouts/ worksheets meant to be used in the lesson should be numbered.

There are two sections in the plan template which refer to the study and use of language, both CALP and BICS. CALP is related to both subject specific vocabulary and grammar structures (patterns, speech acts, performatives/ action verbs, and the patterns they require) used for cognitive processing of the studied material. The subject teacher should negotiate the selection of CALP language 
with the language teacher, and make sure it corresponds to students' cognitive and language level. BICS refers to communication and interaction and is less cognitively demanding than CALP. However, if the proficiency level of students is not high enough, it might pose additional difficulties in communicating during the experimental stage, which can lead to increased mother tongue use and unmotivated code-switch. Both sections in the plan should contain samples of the way teachers scaffold students' understanding of the new content and develop their communication skills. These samples are indicative of the way teachers plan to teach the content of the subject and at the same time work on improving students' language skills.

To sum up, the main recommendations related to planning the lessons are as follows:

- Lesson plan should use clear sequencing and numbering of activities and corresponding worksheets. Although the stages were clearly outlined, the activities for these stages were not always specified. In some cases, the procedures and tasks should be described in more detail.

- Language and subject teachers should work together in planning lesson activities and preparing materials. Their plans should contain a clear distribution of their roles and responsibilities in the lesson.

- In planning the teaching of key vocabulary in STEM lessons and developing students' BISC and CALP, it is important not only to introduce but also to practise and consolidate key verbs and structures which are central to understanding and using science discourse.

- The duration of each stage or sub-stage in the lesson which was missing in some of the plans should be clearly indicated in order to ensure appropriate time distribution for achieving lesson aims. It is not necessary to do everything that has been planned (and included in the worksheets) - it is better to be flexible and adapt to students' needs, especially at the consolidation stage.

\section{Teaching the lessons - good practices, challenges, and recommendations}

Research in CLIL has provided abundant evidence that there is a lack of cohesion around CLIL 'pedagogies', and that different models and their constituent dimensions have contributed to the emergence of a range of methods, materials and curriculum organisation which respond to educational settings in different countries (see Coyle 2007).

The lessons taught and observed under the project were no exception to this 
finding. The initial aim of the project was to provide language tuition to subject teachers, so that eventually they can teach the subject in the foreign language - German or Spanish respectively. However, due to increased work load and time constraints not all participating subject teachers attended the language courses or learnt the language to the level necessary to give them confidence to teach their subject in the foreign language. It was agreed that in the process of project implementation the teachers can experiment with different forms of collaboration and co-teaching. The idea was for the language teacher to provide more support at the beginning, and then gradually withdraw and give the leading role to the subject teacher.

Lesson observations in different schools revealed the following models of teaching:

- lessons taught in the target language by the language teacher alone without any involvement of the subject teacher, with occasional translation of terms into students' mother tongue provided by the language teacher;

- lessons taught mainly by the language teacher with subject teacher assisting groups of students during the experiment and providing guidance to groups and individual students in their mother tongue;

- lessons taught mainly by the language teacher in target language with the subject teacher intervening at times to provide input or explanation in students' mother tongue;

- lessons taught by both teachers speaking target language and mother tongue in turns or simultaneously;

- lessons taught by the subject teacher alone mainly in students' mother tongue with terminology given in the target language in worksheets;

- lessons taught by the subject teacher alone in the target language with occasional translation of terminology, with the language teacher present but not intervening.

The choice of a teaching model in each school depended on several main factors:

- the willingness and desire of the language teacher to experiment with something new /a subject lesson with the use of a mobile lab/, based on teacher's personal qualities, self-esteem and risk taking;

- the language level of the students - in some schools the students 
had begun to study the language a few months before joining the project, and their language level was not high enough to understand a lesson in the foreign language;

- subject teacher's willingness and readiness to teach the lesson in the target language which $\mathrm{s} / \mathrm{he}$ is currently studying;

- both language and subject teachers' willingness to cooperate in planning and teaching the lesson together.

The observations identified a number of positive aspects and good practices in the teaching models demonstrated in the schools. It can be said that the covered content was suitable for students' needs, interests, and cognitive level both in terms of the subject matter and the target language. The students were motivated to explore and make discoveries in the science domain and teach teachers provided suitable scaffolding for developing students' CALP and BICS skills. Although some of the topics were familiar to the students as they were studied in the respective subject classes, it had a positive role in the classes where the target language proficiency was not high.

The lessons were based on interesting, motivating, and innovative material which appealed to different students' cognitive/ learning styles and intelligences. In most lessons there was a variety of activities and interaction patterns, which shows that the teachers together managed to change the traditional routine of teaching in a frontal way only.

Most observed lessons successfully incorporated the use of mobile labs for providing hands-on experience to support learning of subject matter knowledge and target language, and the teachers tried to provide a smooth transition through the 5 steps of STEM inquiry: trigger - hypothesis - experimentation verification/ conclusion - generalisation/ transfer.

Cooperation between subject and language teachers facilitated their mutual learning; language teachers had a good array of methodological tools, and the subject teachers were willing to use these tools in their teaching and try to speak the foreign language.

The teachers had a good rapport with the students and created a good working environment. They motivated and encouraged learners to explore the topic, experiment, discuss and report their findings. They also praised students for their efforts and results which was very important as the students were involved in a new type of lesson they were not familiar with. The most important factor for achieving success was the teachers' willingness to face the challenges of working together and co-teaching with another subject/ language teacher. The cooperation was extended beyond the classroom, as the teachers were open and willing to discuss the lessons with the observers and with other teachers from 
their school and the other schools involved in the project.

Observing students at work, revealed that they had the intrinsic motivation to study the subject matter in a foreign language and to work with the mobile labs. Moreover, they had a positive attitude and respect for their teachers and were ready to work with them in this new type of lesson. Students actively contributed to the good working atmosphere by being cooperative and willing to work in teams and pairs. Most of them demonstrated good enough command of the target language both in terms of BICS and CALP.

Along with the good practices observed in the lessons, some issues and challenges for the teachers had been identified, which were discussed with the teachers after the observations.

One of the main problems seemed to result from poor planning of the subject and the language teacher's part in the lesson. Clear role and responsibilities distribution would have helped avoid confusion and overlapping. When both teachers teach the lesson, there needs to be a balance between their participation and clear transitions between their activities.

Another issue was language use. As Coyle, points out "whilst the ' $\mathrm{C}$ ' representing communication takes into account linguistic elements such as grammar, it also includes a wider interpretation of communication for learning which accommodates issues such as the use of the mother tongue and codeswitching" (Coyle 2007: 552). However, code switching (when present in the lessons) was not always motivated and balanced. In principle, classroom language should be the target language, not students' and teachers' mother tongue.

Another issue is that the teachers should not talk simultaneously in two different languages as this distracts students and disrupts their work. The subject teachers speaking L1 should limit their talking time and modify the manner in which subject matter is presented (e.g. being as detailed as possible and requiring full sentences in response). In this way there will be more time for target language focus and practice.

In some fragments of lessons taught mainly by subject teachers in L1, the language teacher's role was simply to provide language support through unnecessary translation. This should be avoided, as it distracts students and makes their task less challenging.

As for the students, there should be more interaction among them while doing the experiment or task. Students need to be given enough time for speaking the target language, especially when they describe the experiment and present their findings and conclusions. This is in line with Coyle's observation that promoting interactivity also has repercussions for classroom learning cultures where learner - learner interaction and specific scaffolded teacher support may 
not be in the usual repertoire or classroom routines of either teachers or learners (Coyle 2007). Both teachers should step back and let students work, discover, and think for themselves. They should facilitate, guide, and monitor students at work rather than engaging them in listening to theoretical input or giving additional instructions while they are working.

\section{Conclusion}

To sum up, there is still a lot of work to be done by both subject and language teachers in order to overcome the difficulties inherent in CLIL implementation. The observations confirmed the fact that teaching a subject in a foreign language requires a specialist pedagogical expertise from both teachers. Language teachers might need to learn to talk in an especially comprehensible way, to teach a lot of academic vocabulary, to help learners listen in a foreign language, and give them feedback, to help learners speak the target language when working in groups or pairs, read more complex subject texts, and write summaries or conclusions. Subject teachers who use the target language can get advice on how to do these things from the language teachers while thinking about and planning the lesson together. Language teachers can advise subject teachers on their own language use, on the language demands of their subjects and on the kinds of language support and practice which the subject teachers can incorporate into their lessons. Subject teachers do not simply need to improve the level of their language - they need to be familiar with and use foreign language teaching methodology, especially the principles and practice of communicative language teaching and task-based learning. Finally, different models of collaboration between teachers in class might be used and experimented with in different lessons, so that the most suitable models be found for each specific teaching and learning context. This collaboration can be effected and further supported by the "construction of communities of CLIL practitioners" (Coyle 2014:556), where "participants engage in 'co-exploring' theories of practice which are rooted in what they do and why, yet also guided by knowledgeable others who signpost relevant practice already in the field for critique" (ibid). Further research in the area is needed and working together on projects is one way forward to building much needed evidence and reflecting on it to overcome challenges.

\section{References:}

Buckley 2000. Buckley F. Team-teaching: What, why and how? Thousand Oaks, CA: Sage Publications, 2000.

Coyle 2006. Coyle D. "Content and Language Integrated Learning. Motivating Learners and Teachers. 2006. <blocs.xtec.cat/clilpractiques1/files/2008/11/slrcoyle.pdf>.

Coyle 2007. Coyle D. "Content and Language Integrated Learning: Towards a Connected Research Agenda for CLIL Pedagogies". International Journal of Bilingual Education and 
Bilingualism. 10 (5): 543-562.

Coyle, Hood, Marsh 2010. Coyle D., Hood P., D. Marsh. CLIL: Content and Language Integrated Learning. New York: Cambridge University Press, 2010.

Cummins 2001. Cummins J. Negotiating Identities: Education for Empowerment in a Diverse Society. 2nd ed. Los Angeles: California Association for Bilingual Education, 2001.

Dalton-Puffer 2008. Dalton-Puffer C. "Outcomes and Processes in Content and Language Integrated Learning: Current Research in Europe”. In Delanoy W., L. Volkmann (Eds.). Future Perspectives in English Language Teaching. Heidelberg: Carl Winter, 2008. 7- 23.

Euridice 2006. Eurydice: The information network on education in Europe. Content and Language Integrated Learning (CLIL) at School in Europe. Brussels: European Commission, 2006.

Euridice Network 2012. Euridice Network. Key Data on Teaching Languages at School in Europe. Brussels: European Commission, 2012.

Lorenzo 2007. Lorenzo F. "The Sociolinguistics of CLIL: Language Planning and Language Change in 21st Century Europe". RESLA 1, 2007. 27-38.

Maroney 1995. Maroney S. “Team Teaching”. 1995. <http://www.wiu.edu/users/mfsam1/ TeamTchg.html $>$.

Munoz 2007. Munoz C. "CLIL: Some Thoughts on its Psycholinguistic Principles". RESLA 1, 2007. 17-26.

Perez-Canado 2012. Pérez-Canado M. "CLIL Research in Europe: Past, Present, and Future". International Journal of Bilingual Education and Bilingualism, 15:3. 2012. 315341. <http://dx.doi.org/10.1080/13670050.2011.630064>.

Ronfeldt, Farmer, McQueen, Grissom 2015. Ronfeldt M., Farmer S., McQueen K., J. Grissom. "Teacher Collaboration in Instructional Teams and Student Achievement". American Educational Research Journal. 52 (3). June 2015. 475-514.

Sandholtz 2000. Sandholtz J. "Interdisciplinary Team Teaching as a Form of Professional Development". Teacher Education Quarterly, 27(3). 2000. 39-50.

Wolff 2007. Wolff D. "CLIL: Bridging the Gap between School and Working Life". In Marsh D., D. Wolff (Eds.). Diverse Contexts - Converging Goals. Frankfurt: Peter Lang, 2007. 15-25. 